\title{
DADOS BIOMETRICOS EM ESQUISTOSSOMÓTICOS ADULTOS, BAHIA (BRASIL)*
}

\author{
José Tavares-Neto** \\ Eduardo Forleo-Neto*** \\ Ernesto Wilhelms-Neto**** \\ Aluizio Prata**
}

\begin{abstract}
TAVARES-NETO, J. et al. Dados biométricos em esquistossomóticos adultos, Bahia (Brasil). Rev. Saú. de públ., S. Paulo, 22:288-91, 1988.

RESUMO: De dezessete individuos esquistossomóticos, hepatosplênicos, pareados com outros dezessete controles, hepatointestinais, da mesma região, foram aferidas 17 medidas antropométricas. Todas as pessoas tinham de 21 a 50 anos de idade. Esta e outros critérios foram previamente estabelecidos como fatores de pareamento, de inclusão e exclusão no estudo. Porém, não se observou diferenças estatísticas entre as médias dos dois grupos de pacientes.
\end{abstract}

UNITERMOS: Esquistossomose, mansônica. Antropometria. Grupos controle.

\section{INTRODUÇÃO}

O atraso no desenvolvimento somático dos portadores da esquistossomose hepatosplênica tem sido freqüentemente relatado (Marques 5 , 1944; Pessoa $^{8}$, 1953; Ferreira ${ }^{3}$, 1957; Nabawy e col $^{6}$, 1961; Carvalho e Horwith ${ }^{1}$, 1972: Sucupira e Pupo ${ }^{11}, 1976$ e Prata $\left.{ }^{10}, 1982\right)$. Sucupira e Pupo"l (1976) não encontraram alterações endócrinas nos hepatosplênicos e especularam sobre o efeito da desnutrição, explicando o hipodesenvolvimento físico desses indivíduos.

No entanto, a dificuldade em controlar a influência do estado nutricional dos pacientes tem origem na heterogeneidade das amostras; inclusive com respeito à procedência variada do grupo controle, muitas vezes inexistente. Por outro lado, a nossa observação corrente em estudos longitudinais era que o hipodesenvolvimento físico se mantém muito raramente nos indivíduos adultos, hepatosplênicos, em amostras não selecionadas.

Para avaliar o desenvolvimento físico dos indivíduos hepatosplênicos planejamos um estudo pareado, com o objetivo de minimizar o efeito da nutrição, com a aferição de algumas medidas antropométricas.

\section{CASUÍSTICA E MÉTODOS}

Os indivíduos foram selecionados, em maio de 1986, na população do município de Catolândia, cidade do oeste do Estado da Bahia eárea hiperendêmica da esquistossomose onde o hospedeiro intermediário é a Biomphalaria glabrata (Tavares-Neto ${ }^{12}, 1987$ ).

$\mathrm{Na}$ amostra inicial, 26 indivíduos hepatosplênicos (HE) foram pareados aos controles $(\mathrm{n}=26)$, por sexo, idade ( \pm 3 anos), nível sócio-econômico e local de residência (sede-cidade de Catolândia ou fazendas-próximas). A idade variava entre 21 a 50 anos, e os HE fora dessa faixa etária foram previamente excluídos. Nessa área de estudo estavam matriculadas 1.649 pessoas (Tavares-Neto ${ }^{12}, 1987$ ), sendo a população examinada, periodicamente, no período de 1976 a 1986 (6. exame clínico, de fevereiro a abril).

Consideramos como portador da forma hepatosplênica da esquistossomose mansônica (HE), os indivíduos com baço no rebordo costal ou além, sem manobras inspiratórias (Pra$\left.\mathrm{ta}^{10}, 1970\right)$. Os controles hepatointestinais (HI) não tinham baço palpável, mesmo à inspiração profunda e nem o lobo hepático esquerdo no-

\footnotetext{
* Realizado com suporte financeiro do Conselho Nacional de Desenvolvimento Científico e Tecnológico (CNPq). Processo n: 0172.0250/85 e Walter Reed Institute. Processo Umb/Walter Reed (Convênio).

** Núcleo de Medicina Tropical e Nutrição/UnB e Faculdade de Medicina do Triângulo Mineiro - Praça Thomaz Ulhoa, 706 - 38025 - Uberaba, MG - Brasil.

*** Acadêmico de Medicina da Universidade de Brasília - Brasília, DF - Brasil.

**** Estudante de Educação Física da Universidade de Brasília - Brasília, DF - Brasil.
} 
dular e/ou proeminente, nas avaliaçðes clínicas anteriores (Tavares-Neto ${ }^{12}, 1987$ ). Essas lormas clínicas estavam presentes na época do $6^{\circ}$ exame clínico periódico. Até junho de 1986, todos os indivíduos amostrados tinham dois a quatro tratamentos com oxamniquine; em maio daquele ano foi realizado o quarto tratamento em massa, da população. A partir de 1976, na área do projeto, foram realizados, por indivíduo matriculado, de dois a quatorze exames parasitológicos de fezes, pelo metodo de Kato-Katz (Tavares-Neto ${ }^{12}, 1987$ ). Em julho de 1986, todos os indivíduos relacionados tinham fezes sem ovos do Schistosoma mansoni.

$\mathrm{Na}$ época (julho, 1986) do estudo antropométrico, realizado in loco, da amostra inicial, foram excluídos os pares, quando um ou ambos os individuos apresentavam as seguintes situações: gravidez, tempo de afastamento da área maior ou igual a 12 meses (antes de completar 21 anos de idade) e doença grave não relacionada à esquistossomose, antes de completar 21 anos. Desse modo, a amostra final foi de 17 hepatosplênicos e 17 controles.

Todas as medidas antropométricas foram realizadas pelo mesmo observador (EWN), que desconhecia o diagnóstico dos pacientes, utilizando-se dos seguintes aparelhos: plicômetro, taquímetro antropométrico, antropômetro, balança de mola e trena antropométrica. Assim, de cada indivíduo tomou-se as seguintes medidas: peso, altura, segmento superior e inferior, envergadura, circunferência torácica, perimetro do pulso direito, dobras cutâneas (triceps, subescapular, supra-iliaca, abdominal e perna) diâmetros (punho, úmero e fêmur) e perímetros (braço e perna). Essas medidas foram tomadas de pacientes despidos, observando-se as recomendações uniformemente, inclusive quanto à postura e tempo de respiração (De Rose e col. ${ }^{2}$, 1984). Com bases naquelas medidas, foram calculados percentagem de gordura, peso de gordura, peso limpo, peso ósseo, peso residual, peso muscular e compleição física (De Rose e col. $\left.{ }^{2}, 1984\right)$. A reprodutividade das medidas foi previamente avaliada em dez pessoas e em duas ocasiões diferentes; o nível de erro era inferior a $2 \%$.

Os resultados foram analisados no Centro de Processamento de Dados da Universidade de Brasilia (CPD/UnB), através do programa SPSS-v8, e em todos os cálculos trabalhou-se com cinco dígitos decimais. Os números foram ajustados nas tabelas em uma casa decimal, para efeito de simplificação. A hipótese Ho seria rejeitada com $\mathrm{P}<0,05$.

\section{RESULTADOS}

Os indivíduos, de cada par, tinham nível sócio-econômico semelhante. Cada grupo de pacientes era constituído por nove mulheres e oito homens; entre os HE a idade variou de 21 a 49

\section{TABELA 1}

Medidas antropométricas dos esquistossomóticos, hepatosplênicos (HE) e hepatointestinais (HI), de Catolândia - Bahia.

\begin{tabular}{|c|c|c|c|c|c|c|}
\hline \multirow{2}{*}{$\begin{array}{l}\text { Pacientes } \\
\text { Medidas }\end{array}$} & \multicolumn{2}{|c|}{$\mathrm{HE}(\mathrm{n}=17)$} & \multicolumn{2}{|c|}{$\mathrm{HI}(\mathrm{n}=17)$} & \multirow[b]{2}{*}{$\mathrm{F}^{\mathrm{b}}$} & \multirow[b]{2}{*}{$t_{32}^{b}$} \\
\hline & $\bar{X}$ & DP & $\bar{X}$ & DP & & \\
\hline Peso (kg) & 53,1 & 6,3 & 52,7 & 7,7 & 1,48 & 0,17 \\
\hline Altura $(\mathrm{cm})$ & 158,6 & 8,2 & 157,4 & 9,0 & 1,20 & 0,42 \\
\hline Segmento superior $(\mathrm{cm})$ & 79,8 & 2,7 & 78,7 & 3,1 & 1,34 & 1,15 \\
\hline Segmento inferior $(\mathrm{cm})$ & 78,8 & 5,9 & 78,2 & 5,6 & 1,10 & 0,30 \\
\hline Envergadura $(\mathrm{cm})$ & 163,0 & 13,1 & 160,8 & 12,5 & 1,09 & 0,51 \\
\hline Circunferência torárica $(\mathrm{cm})$ & 84,2 & 4,8 & 84,1 & 3,8 & 1,57 & 0,05 \\
\hline Perímetro Pulso Direito $(\mathrm{cm})$ & 15,2 & 0,9 & 15,0 & 0,9 & 1,20 & 0,40 \\
\hline Dobra do tríceps (mm) & 10,4 & 6,9 & 13,2 & 8,2 & 1,38 & 1,10 \\
\hline Dobra subescapular (mm) & 10,9 & 6,2 & 15,2 & 7,8 & 1,60 & 1,75 \\
\hline Dobra supra-ilíaca (mm) & 8,8 & 6,1 & 10,4 & 4,5 & 1,86 & 0,87 \\
\hline Dobra abdominal (mm) & 14,4 & 8,2 & 17,1 & 8,4 & 1,06 & 0,97 \\
\hline Dobra perna $(\mathrm{mm})$ & 9,2 & 5,4 & 9,6 & 5,2 & 1,08 & 0,23 \\
\hline Diâmetro do punho $(\mathrm{cm})$ & 5,2 & 0,4 & 5,3 & 0,4 & 1,02 & 0,57 \\
\hline Diâme tro do úmero $(\mathrm{cm})$ & 6,3 & 0,5 & 6,4 & 0,5 & 1,23 & 0,48 \\
\hline Diâmetro do fêmur $(\mathrm{cm})$ & 8,7 & 0,5 & 8,7 & 0,7 & 1,90 & 0,14 \\
\hline Perímetro do braço $(\mathrm{cm})$ & 27,3 & 2,5 & 27,8 & 2,5 & 1,04 & 0,58 \\
\hline Perímetro da perna $(\mathrm{cm})$ & 32,8 & 1,9 & 33,0 & 2,4 & 1,58 & 0,31 \\
\hline
\end{tabular}

(a) $\bar{X}$ média e DP (Desvio Padrão); (b) Significância estatística $(P \leqslant 5 \%$ ) se $F \geqslant 2,33$ e $t \geqslant 2,04$. 
TABELA 2

Fracionamento do peso total e a compleição física dos esquistossomóticos, de Catolândia - Bahia

\begin{tabular}{|c|c|c|c|c|c|c|}
\hline \multirow{2}{*}{$\begin{array}{l}\text { Pacientes } \\
\text { Medidas }\end{array}$} & \multicolumn{2}{|c|}{$\mathrm{HE}(\mathrm{n}=17)$} & \multicolumn{2}{|c|}{$H I(n=17)$} & \multirow[b]{2}{*}{$\mathrm{F}^{\mathrm{b}}$} & \multirow[b]{2}{*}{$\mathrm{t}_{32} \mathrm{~b}$} \\
\hline & $\overline{\mathrm{X}}$ & DP & $\bar{X}$ & DP & & \\
\hline Peso de gordura (kg) & 6,8 & 2,5 & 7,5 & 2,1 & 1,47 & 0,91 \\
\hline Peso ósseo $(\mathrm{kg})$ & 9,0 & 1,3 & 9,0 & 1,6 & 1,46 & 0,01 \\
\hline Peso residual (kg) & 11,9 & 1,9 & 11,9 & 2,4 & 1,53 & 0,07 \\
\hline Peso muscular (kg) & 25,4 & 2,6 & 24,3 & 3,8 & 2,04 & 0,99 \\
\hline Peso limpo $(\mathrm{kg})$ & 46,3 & 5,4 & 45,2 & 7,4 & 1,90 & 0,51 \\
\hline Percentagem de gordura & 12,6 & 3,9 & 14,3 & 3,9 & 1,01 & 1,30 \\
\hline Compleição física & 10,5 & 0,6 & 10,5 & 0,4 & 2,75 & $0,08^{\mathrm{C}}$ \\
\hline
\end{tabular}

(a) $\bar{X}$ (média) e DP (Desvio Padrão); (b) Significância estatística $(p \leqslant 0,05)$ se $F \geqslant 2,33$ e $t \geqslant 2,04$; (c) graus de liberdade para amostra heterocedásticas.

anos, média de $32,6 \pm 8,0$ e os HI com idade variando de 21 a 50 anos $(31,7 \pm 7,7)$. A variância da idade dos dois grupos foi semelhante $(F=$ $1,08 ; \mathrm{p}>0,88)$, bem como as médias $\left(\mathrm{t}_{32}=\right.$ $0,35 \mathrm{p}>0,73$ ).

$\mathrm{Na}$ Tabela 1, a média $(\overline{\mathrm{X}})$ e o desvio padrão (DP) das 17 medidas antropométricas foram listadas nos dois grupos de pacientes; entre eles não se observou diferença estatisticamente. As demais medidas calculadas, a partir daquelas, como o fracionamento do peso total e a compleição física, foram relacionadas na Tabela 2 . Também, para essas medidas, os dois grupos de indivíduos não diferiram, não obstante, as variancias da compleição física ficarem no limite de significância estatística, sendo as médias semelhantes. Desse modo, com base nos dados apresentados, pode-se inferir que os individuos hepatosplênicos e hepatointestinais têm medidas antropométricas semelhantes $\left(\mathrm{Ho}: \overline{\mathrm{X}}_{1}=\right.$ $\bar{X}_{2}$ ).

\section{DISCUSSĀO}

Em estudo como esse, com alguns critérios de inclusão e exclusão, o tamanho da amostra fica reduzido; conseqüentemente pode ser causa de distorção na análise. Por isso, também, os indivíduos não foram comparados entre os grupos raciais, apesar das diferenças antropométricas conhecidas (Oliveira e Azevêdo ${ }^{7}$, 1977), inclusive em relação à forma hepatosplênica da esquistossomose mansônica (Tavares-Neto ${ }^{12}$, 1987).

Nossos dados corroboram a hipótese de não existir fator determinante para a manutenção do hipodesenvolvimento físico no indivíduo adulto hepatosplênico, quando avaliado numa amostra não selecionada. Possivelmente, os casos relatados de hipodesenvolvimento estejam mais relacionados à desnutrição associada (Ferreira ${ }^{3}, 1957$ e Sucupira e Pupo ${ }^{11}, 1976$ ). Apesar dos casos graves, com comprometimento somático e/ou puberal, a esplenectomia (Ferreira ${ }^{3}$ 1957) e terapêutica da esquistossomose, em alguns casos, revertem esse quadro clínico. No entanto, o infantilismo é uma complicação da esquistossomose mansônica, hepatosplênica e com baixa prevalência $\left(\right.$ Prata $\left.^{10}, 1982\right)$; por isso, essa situação clínica é observada muito raramente em estudos semelhantes. Obviamente, em casuísticas hospitalares pode aparecer como problema superdimensionado.

Em áreas hiperendêmicas da esquistossomose, a associação com as enteroparasitoses e a desnutrição crônica é muito habitual. Por certo, esses três fatores provocam sérios danos à economia orgânica, os quais, porém, seriam aparentemente homogêneos, atingindo igualmente esquistossomóticos hepatointestinais $\mathrm{e}$ hepatosplênicos. 
TAVARES-NETO, J. et al. [Biometric data in adult schistosomotics of Catolândia, Bahia, Brazil]. Rev. Saúde públ., S. Paulo, 22:288-91, 1988.

ABSTRACT: Seventeen antropometric measurements were evaluated from seventeen hepatosplenic schistossomotic individuals paired with seventeen control hepato-intestinal schistosomotic patients. All of them were from the same region, and all of them belonged to an age group ranging from 21 to 50 years. Age and other criteria were previously established, such as pairing factors, to determine inclusion in or exclusion, from the study. However, statistical differences were not observed between the averages of the two groups of patients.

UNITERMS: Schistosomiasis mansoni. Anthropometry. Control groups.

\section{REFERÊNCIAS BIBLIOGRÁFICAS}

1. CARVALHO, A.C.M. \& HORITH, M. Hepatoesplenic schistosomiasis mansoni associated with retarded growth and sexual development: endocrine evaluation. Gaz. med. Bahia, 72:69-84, 1972.

2. DE ROSE, E.H.; PIGATTO, E.; DE ROSE, R.C.F. Cineantropometria educação física e treinamento desportivo. Brasilia, Ministério da Educação e Cultura/SEED, 1984. p. 15-28, 39-58.

3. FERREIRA, J.M. Aspectos endócrinos da esquistossomose mansônica hepatosplênica. São Paulo, 1957. [Tese de Livre Docência - Faculdade de Medicina da USP].

4. GORDON, A.S.; KLEINBERG, W.; CHARIPPER, H.A. The reticuloendothelial system and hormone refractorines. J. exper. Med., 70:333-6, 1969.

5. MARQUES, A. Infantilismo esplènico. Rev. med. $P a$ nama., 2:213.24, 1944.

6. NABAWY, M.; GABR, M.; RAGAB, M. Effects of bilharziasis on development of Egyptian children. J. trop. Med. Hyg., 4:271-7, 1961.

7. OLIVEIRA, M.P.M. \& AZEVEDO, E.S. Racial differences in anthropometric traits in school children of Bahia, Brazil. Amer. J. phys. Anthrop., 46:471-6, 1977.

8. PESSOA, S.B. Considerações sobre a esquistossomose na infância. Rev. Med. Cirurg. S. Paulo, 13:29-35, 1953.

9. PRATA, A. Como caracterizar a forma hepatosplênica da esquistossomose? In: Simpósio sobre Esquistossomose, 2:, Salvador, 1969. Salvador, Ministério da Marinha/Universidade Federal da Bahia, 1970. p. 179.

10. PRATA, A.R. Esquistossomose mansoni. In: Veronesi, R., ed. Doenças parasitárias e infecciosas. $7^{a}$ ed. Rio de Janeiro, Guanabara Koogan, 1982. p. 884-904.

11. SUCUPIRA, M.S. \& PUPO, A. Estudos hormonais do hipodesenvolvimento somático e puberal de portadores de esquistossomose mansônica. Rev. Ass, med. bras., 22:154-61, 1976.

12. TAVARES-NETO, J. Recorrência familial e a composição racial na esquistossomose mansônica. Brasilia, 1987. [Dissertação de Mestrado - Universidade de Brasília].

Recebido para publicação em 12/11/1987 Reapresentado em 5/5/1988 Aprovado para publicação em $9 / 5 / 1988$ 